Check for updates

Cite this: Phys. Chem. Chem. Phys., 2020, 22, 27732

Received 18th August 2020, Accepted 13th November 2020

DOI: $10.1039 / \mathrm{d} 0 \mathrm{cp} 04386 \mathrm{a}$

rsc.li/pccp

\section{Cryogenic ion trap vibrational spectroscopy of the microhydrated sulfate dianions $\mathrm{SO}_{4}{ }^{2-}\left(\mathrm{H}_{2} \mathrm{O}\right)_{3-8}{ }^{\dagger}$}

\author{
Harald Knorke, (D) $\ddagger^{\mathrm{a}}$ Huiyan Li, $\ddagger^{\mathrm{bc}}$ Jonas Warneke, (iD a Zhi-Feng Liu* ${ }^{\mathrm{bc}}$ and \\ Knut R. Asmis iD *a
}

\begin{abstract}
Infrared photodissociation spectra of the $\mathrm{D}_{2}$-tagged microhydrated sulfate dianions with three to eight water molecules are presented over a broad spectral range that covers the $\mathrm{OH}$ stretching and $\mathrm{H}_{2} \mathrm{O}$ bending modes of the solvent molecules at higher energies, the sulfate stretching modes of the solute at intermediate energies and the intermolecular solute librational modes at the lowest energies. A low ion temperature combined with messenger-tagging ensures well-resolved vibrational spectra that allow for structure assignments based on a comparison to harmonic and anharmonic IR spectra from density functional theory (DFT) calculations. DFT ab initio molecular dynamics simulations are required to disentangle the broad and complex spectral signatures of microhydrated sulfate dianions in the $\mathrm{OH}$ stretching region and to identify systematic trends in the correlation of the strength and evolution of the solute-solvent and solvent-solvent interactions with cluster size. The onset for the formation of the second solvation shell is observed for $n=8$.
\end{abstract}

\section{Introduction}

The sulfate dianion, $\mathrm{SO}_{4}{ }^{2-}$, is among the best studied anions, since it plays an important role in diverse areas such as in atmospheric processes, e.g. sulfate aerosol formation and chemistry in the upper troposphere, in the regulation of metabolic and cellular processes, or in astrogeochemistry. ${ }^{1-3}$ Due to its compact, doubly charged nature, the interaction of sulfate with water is strong and consequently it is classified as one of the most cosmotropic anions in the Hofmeister series. ${ }^{4}$ A fundamental understanding of its role in nature relies on a molecular-level understanding of how its intrinsic properties are influenced by solvation. Gas phase spectroscopy of massselected ions is particularly useful in obtaining such information, since it allows studying solvation one solvent molecule at a time. Microhydrated sulfate dianions, $\mathrm{SO}_{4}{ }^{2-}\left(\mathrm{H}_{2} \mathrm{O}\right)_{n}$, represent important model systems, since they are amenable to high level electronic structure calculations. ${ }^{5-9}$

Blades and Kebarle reported the first mass spectrometric studies on gaseous $\mathrm{SO}_{4}{ }^{2-}\left(\mathrm{H}_{2} \mathrm{O}\right)_{n}$ clusters. ${ }^{5}$ They showed that at least three water molecules are necessary to stabilize the

\footnotetext{
${ }^{a}$ Wilhelm-Ostwald-Institut für Physikalische und Theoretische Chemie, Universität Leipzig, Linnéstr. 2, 04103 Leipzig, Germany. E-mail: knut.asmis@uni-leipzig.de

${ }^{b}$ Department of Chemistry and Centre for Scientific Modelling and Computation, Chinese University of Hong Kong, Hong Kong, China. E-mail: zfliu@cuhk.edu.hk ${ }^{c}$ Shenzhen Research Institute, Chinese University of Hong Kong,

No. 10, 2nd Yuexing Road, Shenzhen, China

$\dagger$ Electronic supplementary information (ESI) available. See DOI: 10.1039/d0cp04386a

\# These authors contributed equally.
}

dianion, while smaller clusters are prone to either electron autodetachment or proton transfer and formation of $\mathrm{HSO}_{4}{ }^{-}$ and $\mathrm{OH}^{-} .5$ Wang and co-workers used anion photoelectron spectroscopy to provide an estimate of the repulsive Coulomb barrier and hydration energies for up to $n=40 .^{7,10-12}$ Williams and co-workers then studied dissociation pathways and energetics up to $n=17$ by mass spectrometric means. ${ }^{13}$ Infrared multiple photon photodissociation (IRMPD) spectra of cryogenically-cooled $\mathrm{SO}_{4}{ }^{2-}\left(\mathrm{H}_{2} \mathrm{O}\right)_{3-24}$ ions at $\sim 20 \mathrm{~K}$ measured in the mid-IR range (550 to $1800 \mathrm{~cm}^{-1}$ ) provided a more detailed insight into the evolution of the cluster structures with size. ${ }^{14}$ Photoelectron spectra of cold anions ${ }^{15}$ as well as IRMPD spectra in the $\mathrm{O}-\mathrm{H}$ stretching region ${ }^{16}$ yielded new insights, initially for $n \leq 7$ and later also for clusters up to $n=80 .^{9,17,18}$ However, the structural assignments for individual cluster sizes remained controversial. For example, the structure of $\mathrm{SO}_{4}{ }^{2-}\left(\mathrm{H}_{2} \mathrm{O}\right)_{6}$ was initially predicted to be of $C_{3}$ symmetry, ${ }^{10}$ then $T_{\mathrm{d}}$ symmetry ${ }^{14}$ and later, a mixture of both isomers was proposed. $^{16}$ Multiple possible structures have also been discussed for $n=5 .^{10,14,15,19,20}$ Such controversial assignments can be resolved using isomer-specific detection schemes. This was demonstrated recently using cryogenic ion trap vibrational spectroscopy (CIVS) in combination with messenger-tagging and the $\mathrm{IR}^{2} \mathrm{MS}^{2}$ excitation scheme. ${ }^{21}$ This yields data with enhanced signal-to-noise ratio and resolution that can be interpreted without complications from multiple photon processes, rovibrational hot bands or population of multiple isomers. With respect to the structure of $\mathrm{SO}_{4}{ }^{2-}\left(\mathrm{H}_{2} \mathrm{O}\right)_{6}$, the initial assignment to a single $C_{3}$-isomer was confirmed. ${ }^{21}$ 
Early computational studies on microhydrated sulfate dianions focused on determining minimum-energy structures and fragmentation/hydration energies of smaller clusters using either density functional theory $(\mathrm{DFT})^{10,16,22}$ or MP2 calculations ${ }^{14,23}$ as well as exploring their dynamic properties using DFT ab initio molecular dynamics (AIMD) simulations. ${ }^{19,24,25}$ Subsequent investigations focused on larger clusters, ${ }^{18,26,27}$ the relationship between charge distribution and stability ${ }^{28}$ and the performance of density functionals. ${ }^{29}$ In 2011, a systematic analysis of the hyperpotential surfaces for $n=3$ to 7 predicted an energetic reordering of low-lying minimum-energy structures. ${ }^{30}$ These were subsequently analyzed using high-level electronic structure calculations including coupled cluster theory and estimates of basis set effects up to the complete basis set limit. ${ }^{31}$

Using the same techniques as in our previous CIVS study on the microhydrated sulfate hexamer, $\mathrm{SO}_{4}{ }^{2-}\left(\mathrm{H}_{2} \mathrm{O}\right)_{6},{ }^{21}$ we now extend this study to the analysis of the vibrational spectra of $\mathrm{SO}_{4}{ }^{2-}\left(\mathrm{H}_{2} \mathrm{O}\right)_{n}$ with $n=3$ to 8 . Our analysis allows for new insights into the structural evolution of microhydrated sulfate dianions with the degree of hydration and how this evolution manifests itself in the particular cluster's IR signature. We consider cold ion data over a broad spectral range in our interpretation and disentangle it using static as well as dynamic computational approaches to account for strong anharmonicities that dominate many of the observed vibrational transitions. After a careful analysis of the structures up to $n=8$, we discuss the difficulties in interpreting spectra in the often neglected $\mathrm{OH}$ stretching region and approaches to derive more detailed information from this spectral range.

\section{Methods}

\subsection{Experimental methods}

IRPD experiments were performed using the $6 \mathrm{~K}$ ion trap triple mass spectrometer described previously. ${ }^{32,33}$ In brief, microhydrated sulfate dianions are produced in a nanospray ion source from a $20 \mathrm{mM}$ solution of sulfuric acid in a $1: 1$ water/acetonitrile mixture. A mass spectrum of this solution is shown in Fig. S1 of the ESI. $\dagger$ The beam of anions is skimmed, collimated in a gas-filled radio frequency (RF) ion guide, mass-selected using a quadrupole mass filter and focused in a RF ringelectrode ion trap, held at a temperature in-between 6 and $300 \mathrm{~K}$ using a closed-cycle helium cryostat. To allow for continuous ion loading and ion thermalization, the trap is continuously filled with buffer gas, either $\mathrm{He}$ (for bare ions) or $\mathrm{D}_{2}$ (for messenger-tagged ions). Many collisions of the trapped ions with the buffer gas provide gentle cooling of the internal degrees of freedom close to the ambient temperature. This typically avoids the production of kinetically trapped species, although there are exceptions. ${ }^{34}$ At sufficiently low ion-trap temperatures, ion-messenger complexes $\mathrm{SO}_{4}{ }^{2-}\left(\mathrm{H}_{2} \mathrm{O}\right)_{n}\left(\mathrm{D}_{2}\right)_{z}$ are formed via three-body collisions. ${ }^{35,36} \mathrm{D}_{2}$ binds to the hydrated sulfate dianions with energies below $6.5 \mathrm{~kJ} \mathrm{~mol}^{-1}$. Every $100 \mathrm{~ms}$, all ions are extracted from the ion trap and focused both temporally and spatially into the center of the extraction region of an orthogonally-mounted double-focussing reflectron time-of-flight (TOF) tandem photofragmentation mass spectrometer. The ion packet is accelerated into the reflectron stage, ions spread out in space according to their mass-to-charge ratio $(\mathrm{m} / \mathrm{z})$ and are refocused at the initial extraction region. Prior to reacceleration towards the MCP detector, ions with a particular $\mathrm{m} / \mathrm{z}$ value are irradiated by a properly timed, widely wavelength tunable IR laser pulse (bandwidth: $2.5 \mathrm{~cm}^{-1}$ ), supplied by an optical parametric oscillator/amplifier (LaserVision: OPO/OPA/ $\mathrm{AgGaSe}_{2}$ ) laser system. ${ }^{37}$ An IRPD spectrum is measured by continuously scanning the laser wavelength, which is monitored online using a HighFinesse WS6-600 wavelength meter, with a scan speed such that an averaged TOF mass spectrum (over 50 laser shots) is obtained every $2 \mathrm{~cm}^{-1}$. Typically, at least three scans are measured and averaged and the photodissociation cross section $\sigma_{\text {IRPD }}$ is determined as described previously. ${ }^{32,33}$ We measured IRPD spectra in two spectral regions, from 700 to $1800 \mathrm{~cm}^{-1}$ and from 2800 to $3800 \mathrm{~cm}^{-1}$.

\subsection{Computational methods}

Electronic structure calculations were performed using the Gaussian 16 rev. A.03 programme. ${ }^{38}$ For cluster sizes $n=3$ to 7 we used previous published geometries ${ }^{15,27,30}$ as initial guesses. For $\mathrm{SO}_{4}{ }^{2-}\left(\mathrm{H}_{2} \mathrm{O}\right)_{8}$ we used the AMOEBA (Atomic Multipole Optimized Energetics for Biomolecular Applications) force field with the TINKER software programme for molecular mechanics and dynamics simulation to explore the energy surface. AMOEBA model parameters for water and sulfate are taken from the publication of Lambrecht et al. ${ }^{30}$ The previous and newly found geometries were used for geometry optimization with subsequent frequency analysis using the B3LYP functional $^{39}$ in combination with the $6-311++\mathrm{G}(3 \mathrm{df}, 3 \mathrm{pd})^{40,41}$ basis set. For specific structures we performed anharmonic frequency calculations using the second-order vibrational perturbation theory (VPT2) method as implemented by Bloino and Barone. $^{42}$ The reported harmonic and anharmonic vibrational frequencies are not scaled. The influence of dispersion interactions was considered by using the D3 version of Grimme's dispersion correction with Becke-Johnson damping. ${ }^{43}$ All $\operatorname{CCSD}(\mathrm{T})$ energies were taken from the literature. ${ }^{31}$

In AIMD simulations, the electronic energy and atomic forces are obtained within the framework of DFT, while the atomic motion is treated within Newtonian mechanics, as implemented in the CP2K package. ${ }^{44}$ The wave functions are expanded in a double zeta Gaussian basis set, while the electron density is expanded in Gaussians and auxiliary plane waves (GPW ${ }^{45}$ with an energy cut-off at 350 Rydberg for the electron density. The atomic cores are modelled by the Goedecker-Teter-Hutter (GTH) type pseudopotentials. ${ }^{46-48}$ The exchange and correlation energy is calculated using the BLYP functional $^{49,50}$ in combination with Grimme's D3 dispersion correction. ${ }^{43}$ A cluster ion is put at the centre of a periodic cubic box, and the effects of the periodic charge density images are corrected by the decoupling technique developed by Martyna and Tuckerman. ${ }^{51}$ The box length is 16 to $20 \AA$ depending on 
the cluster size. The convergence criterion for the SCF electronic procedure is set to be $10^{-7}$ a.u. at each time step. For molecular dynamics, the temperature is controlled by a NoseHoover thermostat, ${ }^{52}$ with a time step of $0.5 \mathrm{fs}$. An equilibration period of up to $15 \mathrm{ps}$ is performed first, while a production run for data collection at $100 \mathrm{~K}$ lasts more than $100 \mathrm{ps}$. A vibrational spectrum can be directly simulated by the Fourier transform of the dipole time-correlation function (DTCF). ${ }^{53}$

For labelling of structures we use the system proposed by Lambrecht et al.: ${ }^{30}$ the label of each individual structure of $\mathrm{SO}_{4}{ }^{2-}\left(\mathrm{H}_{2} \mathrm{O}\right)_{n}$ is given by the $n . s . w-l$ notation, where $n$ refers to the number of water molecules, $s$ to the number of sulphatewater hydrogen bonds (HBs) and $w$ to the number of waterwater HBs. Within each n.s.w category the structures are sorted according to increasing electronic energy, as determined by Lambrecht et al., ${ }^{30}$ and indicated with number $l(l=1,2, \ldots)$.

\subsection{Classification schemes}

Sulfate dianion hydration is governed by the presence of three coordination sites on each of the four $\mathrm{O}$ atoms on the tetrahedral vertices yielding a total of twelve nucleophilic coordination sites. In order to discuss the formation of the hydrogen-bond (HB) network around the sulfate dianion core two classification schemes prove helpful. First, individual water molecules within the cluster can be designated according to their role as $\mathrm{HB}$ acceptor (A) or donor (D). ${ }^{54}$ In maximum coordination, a water molecule accepts two and provides two HBs and is consequently labelled as an AADD- $\mathrm{H}_{2} \mathrm{O}$. Note, the total number of HBs per water molecule is typically less than four in smaller clusters like those discussed here. Second, solvent moieties can be labelled according to the size of the HBed network, i.e. as $\mathrm{W}_{1-4}$ (see Fig. 1). ${ }^{55}$ In general, the $\mathrm{HB}$ network structure of a microhydrated ion is determined by a balance between solute-solvent and solvent-solvent interactions. For multiply charged ions, like the sulfate dianion, the ion-water interaction typically dominates over water-water interactions for small $n$, while the formation of water rings and more extended HB networks is favored for larger $n$.

The simplest motif, $\mathrm{W}_{1}$, consists of a single DD-water molecule donating two $\mathrm{HBs}$ to $\mathrm{SO}_{4}{ }^{2-}$. An ADD- and a DD- $\mathrm{H}_{2} \mathrm{O}$ molecule linked by a single inter-water $\mathrm{HB}$ comprise the $\mathrm{W}_{2}$ motif, which donates three $\mathrm{HBs}$ to $\mathrm{SO}_{4}{ }^{2-}$. Within the $\mathrm{W}_{3}$ motif, three ADD- $\mathrm{H}_{2} \mathrm{O}$ molecules form a ring, interconnected by three equatorial inter-water $\mathrm{HBs}$, and the three axial $\mathrm{OH}$ groups each donate a $\mathrm{HB}$ to $\mathrm{SO}_{4}{ }^{2-}$. The $\mathrm{W}_{4}$ motif contains a four-membered water ring and is typically part of a larger HB network such that each water molecule is at least threefold coordinated (e.g. four ADD- $\mathrm{H}_{2} \mathrm{O}$ 's). The $\mathrm{W}_{3} / \mathrm{W}_{4}$ motifs differ from the smaller motifs in that they contain significant inter-water interactions.

\section{Results and discussion}

The IRPD spectra of $\mathrm{D}_{2}$-tagged $\mathrm{SO}_{4}{ }^{2-}\left(\mathrm{H}_{2} \mathrm{O}\right)_{n}$ dianions with $n=3$ to 8 , measured in the spectral region from 3800 down to $650 \mathrm{~cm}^{-1}$, are shown in Fig. 2. Band positions and assignments a)

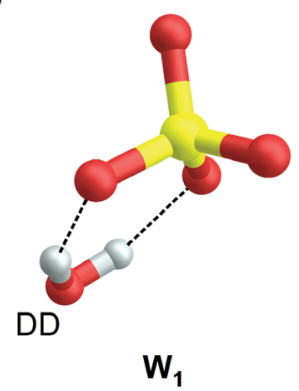

c)

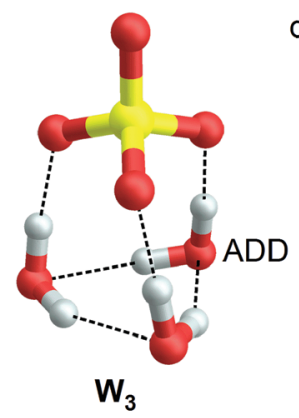

b)

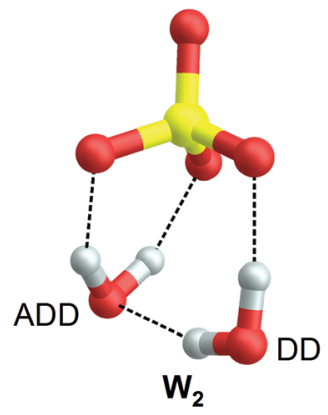

d)

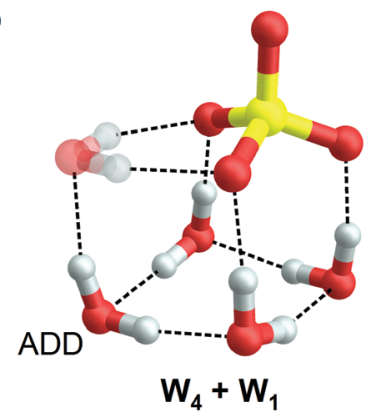

Fig. 1 Four characteristic binding motifs found in microhydrated sulfate dianions: (a) $W_{1}$, (b) $W_{2}$, (c) $W_{3}$ and (d) $W_{4}+W_{1}$ (shown semi-transparent). $\mathrm{W}_{4}$ only appears in combination with other motifs. Note, the depicted structural motifs are not necessarily stable with respect to electron autodetachment.

are listed in Table 1 . The IRPD spectrum for $n=6$ has been reported previously. ${ }^{21}$ The observed features are grouped into seven spectral regions containing the $\mathrm{OH}$ stretching (A to $\mathrm{D}$, 3700 to $3000 \mathrm{~cm}^{-1}$ ), $\mathrm{D}_{2}$ stretching (E, 2970 to $2850 \mathrm{~cm}^{-1}$ ), water bending ( $\mathrm{F}, 1770$ to $1670 \mathrm{~cm}^{-1}$ ), sulfate stretching (G, 1140 to $\left.1020 \mathrm{~cm}^{-1}\right)$ and water wagging modes $\left(\mathrm{H},<900 \mathrm{~cm}^{-1}\right)$. The $\mathrm{OH}$ stretching region is further divided into regions covering the free and quasi-free $\$ \mathrm{OH}$ stretching modes $\left(\mathrm{A},>3615 \mathrm{~cm}^{-1}\right)$ as well as $\mathrm{OH}$ stretching modes involved in very weak $(\mathrm{B}, 3615$ to $3500 \mathrm{~cm}^{-1}$ ), weak (C, 3500 to $3300 \mathrm{~cm}^{-1}$ ) and medium strength (D, 3300 to $3000 \mathrm{~cm}^{-1}$ ) $\mathrm{HBs}^{.54}$

\subsection{Qualitative analysis of the spectra}

3.1.1. OH stretch region. Based on the general appearance of the IRPD spectra in the $\mathrm{OH}$ stretching region three size ranges, namely $n<5, n=5-7$ and $n>7$, are identified. All spectra ( $n=3$ to 8 ) exhibit bands in region $\mathrm{C}$, attributed to $\mathrm{OH}$ oscillators involved in weak HBs. These are characteristic for the presence of isolated $\mathrm{DD}-\mathrm{H}_{2} \mathrm{O}$ molecules as part of the $\mathrm{W}_{1}$ motif. $^{21}$ Bands in region $\mathrm{B}$ and $\mathrm{D}$, characteristic of $\mathrm{OH}$ stretching modes involved in very weak water-water and medium strength anion-water HBs, hinting at the appearance of ADD- $\mathrm{H}_{2} \mathrm{O}$ molecules as part of a three-membered water rings $\left(\mathrm{W}_{3}\right.$ motif), are only observed for $n \geq 5 .{ }^{21}$ In this size range the bands in region $\mathrm{B}$ are rather narrow and remain at the same

$\S$ With quasi-free we mean $\mathrm{OH}$ stretches involved in HBs with HB length larger than $2.5 \AA$. 


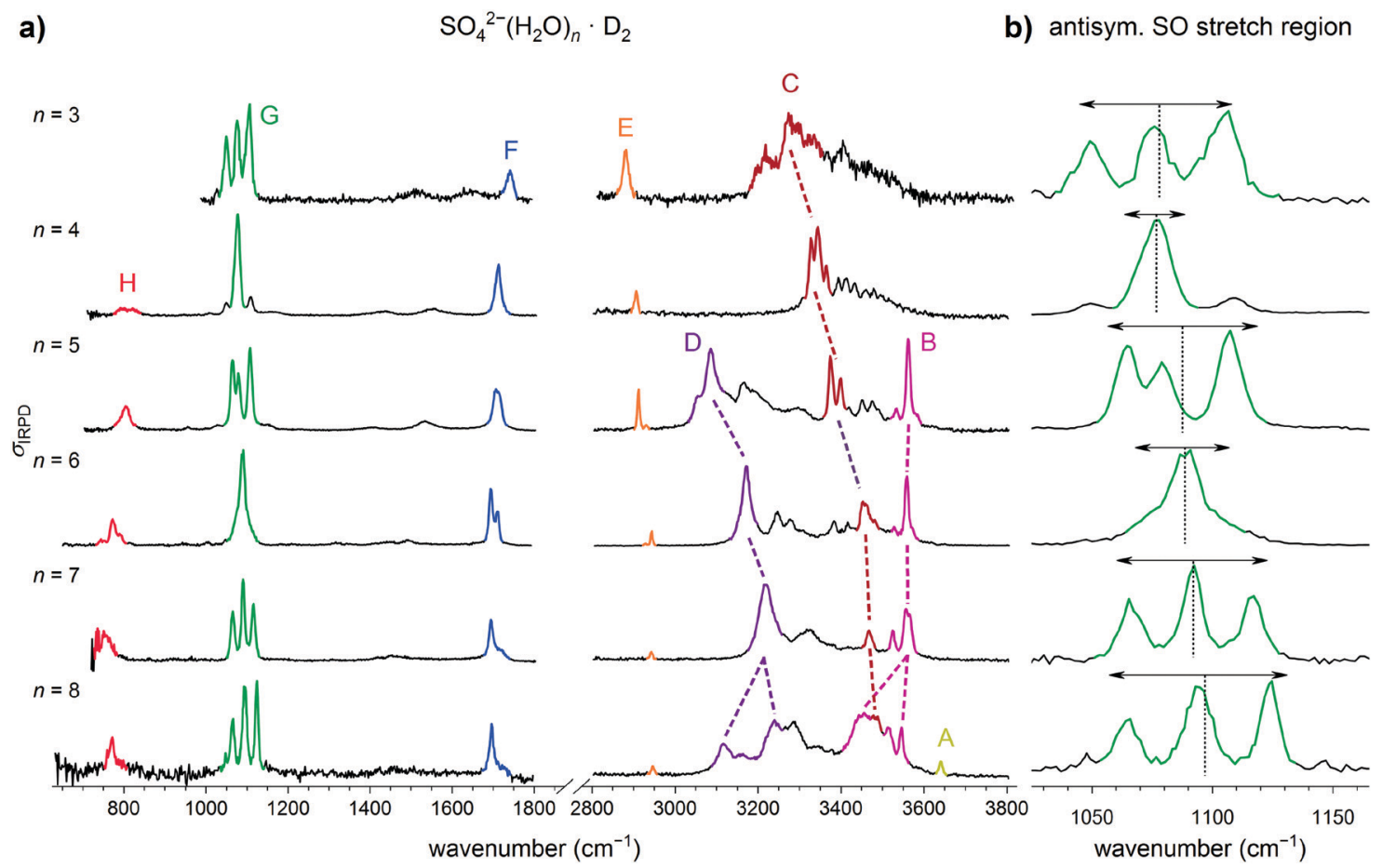

Fig. 2 (a) IRPD spectra of $\mathrm{D}_{2}$-tagged $\mathrm{SO}_{4}{ }^{2-}\left(\mathrm{H}_{2} \mathrm{O}\right)_{n}$ for $n=3$ to 8 covering the fingerprint $\left(650\right.$ to $1800 \mathrm{~cm}^{-1}$ ) and $\mathrm{OH}$ stretching $\left(2800-3800 \mathrm{~cm}^{-1}\right.$ ) spectral regions. (b) Expanded view of the spectral region covering the antisymmetric sulfate stretching modes $\left(1000\right.$ to $\left.1150 \mathrm{~cm}^{-1}\right)$. The weighted mean (dotted line) and the spectral width (double arrow) are shown (see Table S1, ESI $\dagger$ ). The spectrum for $n=6$ has been reported previously. ${ }^{21}$

position with increasing cluster size. In contrast, the bands in region $\mathrm{D}$ are broader and reveal a marked size-dependence: they shift to higher wavenumber with increasing $n$. This is expected, since an increasing number of water molecules compete for the attractive interaction with the dianionic core.
A quasi-free $\mathrm{OH}$ stretching band is only observed in the $n=8$ spectrum, which also reveals a new feature below $3200 \mathrm{~cm}^{-1}$ in region $\mathrm{D}$, suggesting the appearance of a water binding motif not present in the smaller clusters. We will show further below that this is the $\mathrm{W}_{4}$ motif in $n=8$.

Table 1 Band positions (in $\mathrm{cm}^{-1}$ ) and assignments of the features observed in the IRPD spectra of $\mathrm{D}_{2}$-tagged $\mathrm{SO}_{4}{ }^{2-}\left(\mathrm{H}_{2} \mathrm{O}\right)_{n}$ for $n=3$ to 8 shown in Fig. 2

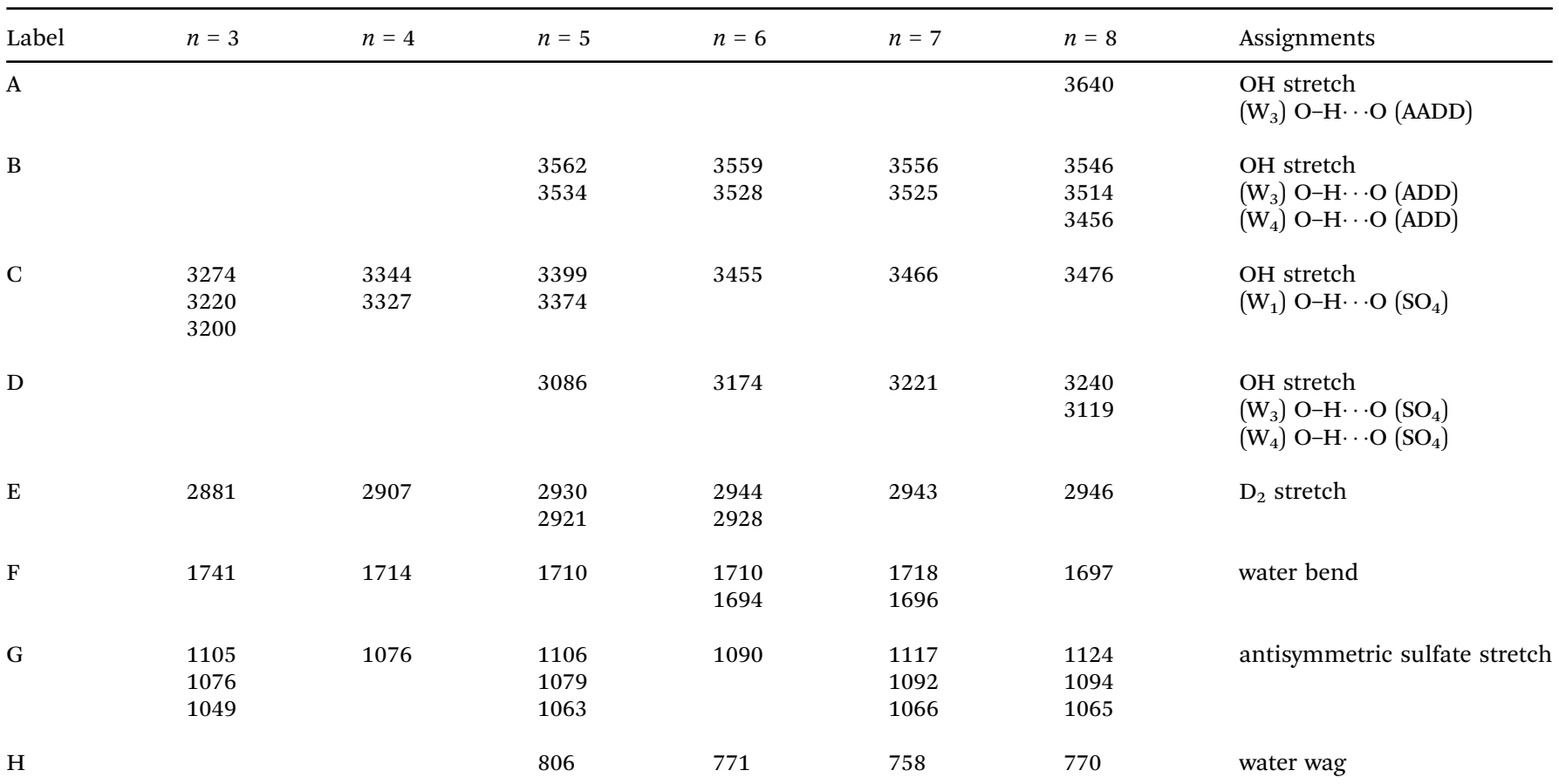


3.1.2. $\mathrm{D}_{2}$ stretch region. A narrow peak in region $\mathrm{E}$ is observed in all the IRPD spectra and assigned to the $\mathrm{D}_{2}$ stretching vibration of the tag. The IR-forbidden transition in isolated $\mathrm{D}_{2}$ (at $\left.2994 \mathrm{~cm}^{-1}\right)^{56}$ gains in intensity in a polar environment. The effect is largest for $n=3$ and decreases with increasing $n$, as the charge density on the sulfate core is more and more delocalized over an extended water network, in return reducing the polarization of the $\mathrm{D}_{2}$ molecule.

3.1.3. Water bend region. The excitation of water bending vibrations is observed in region $\mathrm{F}$. These features shift to lower wavenumbers with increasing microhydration, from $1741(n=3)$ to $1697 \mathrm{~cm}^{-1}(n=8)$, but remain considerably above the water bending band of pure water $\left(1595 \mathrm{~cm}^{-1}\right) .{ }^{57}$ For $n>4$ analysis of the band profile suggests (at least) two bands contribute to this feature, confirming the presence of a more heterogeneous water network in the larger clusters starting at $n=5$.

3.1.4. Sulfate stretch region. Spectral region $\mathrm{G}$ contains the antisymmetric sulfate stretching modes and is very sensitive to the distribution of water molecules around the dianion. ${ }^{14}$ Bare $\mathrm{SO}_{4}{ }^{2-}$ has $T_{\mathrm{d}}$ symmetry, with its four sulfate stretching modes divided into two representations: a totally symmetric, IRforbidden mode $\nu_{\mathrm{S}}$; and the IR-active, triply degenerate antisymmetric stretching mode $\nu_{\mathrm{AS}}$, resulting in a single, intense IR feature. Upon solvation of $\mathrm{SO}_{4}{ }^{2-}$ by water molecules, the threefold degeneracy of $\nu_{\mathrm{AS}}$ can be lifted, depending on the symmetry of the solvation shell, and up to three peaks, corresponding to the three components of $\nu_{\mathrm{AS}}$, are observed, while the IR intensity for exciting $\nu_{\mathrm{S}}$ remains very small. ${ }^{14}$

In qualitative agreement with the previous IRMPD measurements, ${ }^{14}$ but with substantially better resolution and signal-to-noise ratio, we observe a single dominant narrow peak for $n=4$, a slightly broader one for $n=6$, while three features are found for the $n=3,5,7$ and 8, suggesting that the latter ones exhibit a less symmetric solvation environment. The extent of the splitting is found to be largest in $n=8$ and $n=3$ $\left(\geq 72 \mathrm{~cm}^{-1}\right)$. In an attempt to quantify the influence of microhydration on the $\nu_{\mathrm{AS}}$ band, we determined the mean, intensityweighted band position $\bar{x}_{\mathrm{S}}$ as well as the bandwidth $\Delta x_{\mathrm{S}}$, the latter corresponding to the width covering $90 \%$ of the IR intensity (see Table S1 in the ESI $\dagger$ ).

3.1.5. Water libration region. Water wagging modes are excited in the spectral region below $900 \mathrm{~cm}^{-1}$ (region $\mathrm{H}$ in Fig. 2). They are observed for all cluster sizes, but gain in intensity for $n \geq 5$. A clear trend in band position is not observed. The measured bands are considerably sharper than in the previously published IRMPD spectra. It is known that in bulk solutions these libration modes of solvent water molecules are related to long range collective motions and are sensitive to the fluctuation in the HB network. ${ }^{58-60}$ In hydrated bicarbonate clusters, the wagging features were found to be more prominent for $n \geq 6$, when there were significant inter-water $\mathrm{HB}$ connections. ${ }^{61}$ Hence, the present IRPD spectra confirm the presence of such inter-water HBs, presumably as part of ADD binding motifs, ${ }^{21}$ for hydrated sulfate clusters with $n \geq 5$.

A comparison of the present IRPD spectra of $\mathrm{D}_{2}$-tagged $\mathrm{SO}_{4}{ }^{2-}\left(\mathrm{H}_{2} \mathrm{O}\right)_{n}$ to IRMPD spectra of bare $\mathrm{SO}_{4}{ }^{2-}\left(\mathrm{H}_{2} \mathrm{O}\right)_{n}$ dianions ${ }^{14}$ measured in the mid-IR spectral region for $n=3$ to 8 is found in the $\mathrm{ESI}^{\dagger}$ in Fig. S2. Overall, qualitative agreement is found between the two types of spectra, in particular with respect to the band positions, confirming that ions with the same structural motifs are probed. Moreover, the messenger-tag effect on band position and the energetic ordering of the isomers is small and probably negligible. The present spectra are characterized by a better spectral resolution, colder ions and hence narrower bands (see e.g. the spectra for $n=3$, 6 and 8). The relative intensities agree, in general, but on closer inspection, e.g., the antisymmetric sulfate stretching bands for $n=5$ and $n=8$ reveal some differences, probably related to differences in the respective ion internal temperature. Note, weaker bands appear clearer in the present IRPD spectra.

Summarizing, the analysis of the experimental IRPD spectrum of microhydrated sulfate dianions suggests that the $n=4$ dianion contains the most symmetric solvation shell followed by $n=6$, while the structures of the $n=3$ and $n=8$ dianions are the least symmetric. Isolated water molecules $\left(\mathrm{W}_{1}\right.$ motif) are present in all the anions studied and this is the only type of water molecule for $n=3$ and $n=4$. For larger $n$, ADD motifs are also present and evidence for the appearance of a new motif is found for $n=8$.

\subsection{Assignment of IRPD spectra}

3.2.1. IRPD spectra assignment protocol. The assignment of the IRPD spectra of microhydrated sulfate dianions based exclusively on a comparison to simulated harmonic IR spectra is complicated by the presence of pronounced anharmonic and entropic effects in these systems, as we recently demonstrated for $\mathrm{SO}_{4}{ }^{2-}\left(\mathrm{H}_{2} \mathrm{O}\right)_{6} \cdot{ }^{21}$ However, it is computationally demanding to compute anharmonic spectra for all these systems and, indeed, the harmonic spectra do contain useful information in specific spectral regions. It therefore proves helpful to start by defining a general four-step protocol for the assignment of the IRPD spectra, testing it on the smaller systems $(n<6)$ and then applying it to the interpretation of the spectra of larger clusters.

First, we order the lowest energy isomers using the highest quality electronic energies available from the literature and corrected them with ZPEs calculated with B3LYP+GD3BJ/ $6-311++\mathrm{G}(3 \mathrm{df}, 3 \mathrm{pd})$, including dispersion forces. ${ }^{43}$ For $n=3$ to 6 these are the electronic $\operatorname{CCSD}(\mathrm{T}) / \mathrm{CBS}$ energies (CBS: interpolation to the complete basis set limit) from ref. 31 . We find that the lowest energy isomer for $n=3$ to 6 coincides with the one identified in the IRPD spectra in contrast to previous reports. For the larger systems $(n>6)$ we have to revert to ZPE-corrected B3LYP+GD3BJ/6-311++G(3df,3pd) energies, which are less accurate and therefore do not necessarily yield the correct energy ordering. We therefore try to consider all isomers that lie within $10 \mathrm{~kJ} \mathrm{~mol}{ }^{-1}$ of the lowest energy isomer for $n>6$.

Second, we compare the IRPD spectrum of the corresponding $\mathrm{D}_{2}$-tagged anion to harmonic IR spectra, derived from B3LYP frequencies and intensities, of low-energy isomers of the corresponding untagged anion. Messenger-tag effects are neglected here based on the comparison of the IRPD spectra of 
the $\mathrm{D}_{2}$-tagged and the IRMPD spectra of the bare dianions (see above). Indeed, our calculations confirm that tagging has little influence on the sulfate modes, but the shape of the $\mathrm{OH}$ stretching bands can be influenced significantly (see Fig. S4, ESI $\dagger$ ). We find that only the sulfate stretching (1150 to $1000 \mathrm{~cm}^{-1}$ ) and, to a much lesser extent, the water bending (1750 to $1650 \mathrm{~cm}^{-1}$ ) regions are sufficiently diagnostic to exclude a particular isomer from the group of potential candidates based on the comparison to the harmonic spectra.

Third, we compare the IRPD spectrum to B3LYP/VPT2 anharmonic spectra of potential candidates. In favorable cases the general agreement is improved over the comparison to harmonic spectra and allows for the assignment of the remaining features, in particular in the mid-IR region of the spectrum, including overtone and combination bands. Finally, to confirm the structure assignment and to better characterize the spectroscopic signatures of hydrogen bonding in the $\mathrm{OH}$ stretching region, AIMD simulations are performed. Note, these simulations typically do not yield a "perfect" agreement, but do allow for important insights into the factors governing the underlying mechanism responsible for the broadening of the bands in question. In those cases where the more elaborate calculations required for the last two steps are not available, performing the first two steps typically already allows for a tentative assignment.
3.2.2. $\mathrm{SO}_{4}{ }^{2-}\left(\mathrm{H}_{2} \mathbf{O}\right)_{4}$. We start with the $n=4$ system, for which the harmonic as well as both type of anharmonic calculations, the (static) VPT2 and the (dynamic) AIMD approaches, yield consistent results. The structures, relative energies and harmonic IR spectra of five low-energy isomers are compared to the experimental IRPD spectrum in Fig. 3. The VPT2 IR and DTCF spectra of the lowest energy isomer are also shown.

The lowest energy isomer is the highly symmetric $D_{2 \mathrm{~d}}$ structure 4.8.0-1, which adopts a $4 \mathrm{~W}_{1}$ motif. A second, less symmetric $4 \mathrm{~W}_{1}$ structure $\left(\mathbf{4 . 8 . 0 - 2}, C_{\mathrm{s}}\right)$ is found less than $1 \mathrm{~kJ} \mathrm{~mol}^{-1}$ higher in energy. These are followed by the two $\mathrm{W}_{2}+2 \mathrm{~W}_{1}$ structures 4.7.1-1 $\left(+2.3 \mathrm{~kJ} \mathrm{~mol}^{-1}, C_{\mathrm{s}}\right)$ and $\mathbf{4 . 7 . 1 - 2}\left(+2.4 \mathrm{~kJ} \mathrm{~mol}^{-1}\right.$, $C_{1}$ ), which are the lowest energy structures containing an interwater HB. The first $\mathrm{W}_{3}+\mathrm{W}_{1}$ structure (4.5.3-1, $\left.C_{1}\right)$ is predicted at $+4.9 \mathrm{~kJ} \mathrm{~mol}^{-1}$.

The comparison with the harmonic spectra in the sulfate stretching region (see Fig. 3a-e) allows no doubt that the predominant structure observed in the present experiments is the highly symmetric 4.8.0-1 structure, whose IR spectrum is the only one that recovers the single, narrow feature $G_{1}$. The two weak absorption features close to $G_{1}$ at 1051 and $1108 \mathrm{~cm}^{-1}$, which were also observed in the previous IRMPD study, are attributed to the presence of one or more less abundant, lower symmetry isomers. It is remarkable that in



Fig. 3 Comparison of the experimental and computed vibrational spectra of $\mathrm{SO}_{4}{ }^{2-}\left(\mathrm{H}_{2} \mathrm{O}\right)_{4}$ : (a-e) harmonic $\mathrm{B} 3 \mathrm{LYP} / 6-311++\mathrm{G}(3 \mathrm{df}, 3 \mathrm{pd}) \mathrm{IR}$ spectra of five low energy isomers of bare $\mathrm{SO}_{4}{ }^{2-}\left(\mathrm{H}_{2} \mathrm{O}\right)_{4}$, (f) B3LYP/VPT2 IR spectrum of 4.8.0-1, (g) DTCF spectrum of 4.8.0-1 and (h) the IRPD spectrum of $\mathrm{D}_{2}$-tagged $\mathrm{SO}_{4}{ }^{2-}\left(\mathrm{H}_{2} \mathrm{O}\right)_{4}$. Minimum-energy structures, molecular symmetry groups and ZPE-corrected relative CCSD(T) electronic energies (in $\mathrm{kJ}$ mol ${ }^{-1}$ ) are also shown. 
the previous theoretical analysis ${ }^{31}$ three isomers with slightly lower energy (4.7.1-1, 4.8.0-2, and 4.7.1-2) were predicted, each associated with a characteristic triplet of peaks in this spectral region (see Fig. 3b-d), which can account for these two weaker features, but these are limited to contributing less than $20 \%$ to the overall IR signal, based on the predicted harmonic IR intensities. Bands $\mathrm{F}_{1}, \mathrm{H}_{1}$ and $\mathrm{H}_{2}$ are in reasonable agreement with the water bending and two water wagging modes, respectively, of 4.8.0-1, confirming our assignment. Note, none of the harmonic spectra come even close to reproducing the IR signature in the 3000 to $4000 \mathrm{~cm}^{-1}$ region, demonstrating that harmonic $\mathrm{OH}$ stretching frequencies and intensities are, at first glance, not diagnostic and anharmonic effects need to be considered here.

The anharmonic VPT2 spectrum of 4.8.0-1 is shown in Fig. 3f. It represents a significant improvement over the harmonic spectrum in several regards. First, the $\mathrm{OH}$ stretching modes are red-shifted, such that the corresponding bands with the highest intensity now nearly coincide. Second the intensity ratio of bands $G_{1} / F_{1}$ increases, closer to the experimentally observed intensity ratio. Third, the experimental features $\alpha_{1}$ and $\alpha_{2}$ are qualitatively reproduced, suggesting that these can be attributed to combination bands of water wagging modes. Additional combination bands are also predicted in the spectral region below $900 \mathrm{~cm}^{-1}$.
The largest remaining discrepancy between the IRPD spectrum and the VPT2 spectrum of 4.8.0-1 is related to the width of the hydrogen-bonded $\mathrm{OH}$ stretching feature, which extends from 3200 to $3600 \mathrm{~cm}^{-1}$. This is qualitatively recovered when considering dynamic effects as part of an AIMD simulation. Unfortunately, the stability of the $4 \mathrm{~W}_{1}$ motif is underestimated by AIMD, i.e., when the simulation temperature is raised above $30 \mathrm{~K}, \mathbf{4 . 8 . 0 - 1}$ becomes unstable and isomerizes into $\mathrm{W}_{2}+2 \mathrm{~W}_{1}$ structures. However, a DTCF spectrum for 4.8.0-1 can still be obtained by running AIMD at $30 \mathrm{~K}$ and this spectrum is shown in Fig. 3g. The width of this feature is indeed reproduced, confirming a pronounced stretch/rock coupling of the DD water molecules, which we discuss in more detail further below. The exact intensity profile, however, is not obtained, suggesting that (i) nuclear quantum effects ${ }^{21,62}$ and (ii) better functionals, which reproduce the potential surface more accurately, may be required to obtain quantitative agreement.

3.2.3. $\mathrm{SO}_{4}{ }^{2-}\left(\mathrm{H}_{2} \mathrm{O}\right)_{3}$. The structures and relative energies of the five lowest energy structures are shown and their harmonic IR spectra are compared to the IRPD spectrum of $\mathrm{D}_{2}$-tagged $\mathrm{SO}_{4}{ }^{2-}\left(\mathrm{H}_{2} \mathrm{O}\right)_{3}$ in Fig. 4. The energetic ordering of the isomers is identical to that previously reported. ${ }^{31}$ The $C_{2}$-structure $3.6 .0-1$ represents the global ground state. The three isomers lowest in energy all are $3 \mathrm{~W}_{1}$ structures. These are followed by the two $\mathrm{W}_{2}+\mathrm{W}_{1}$

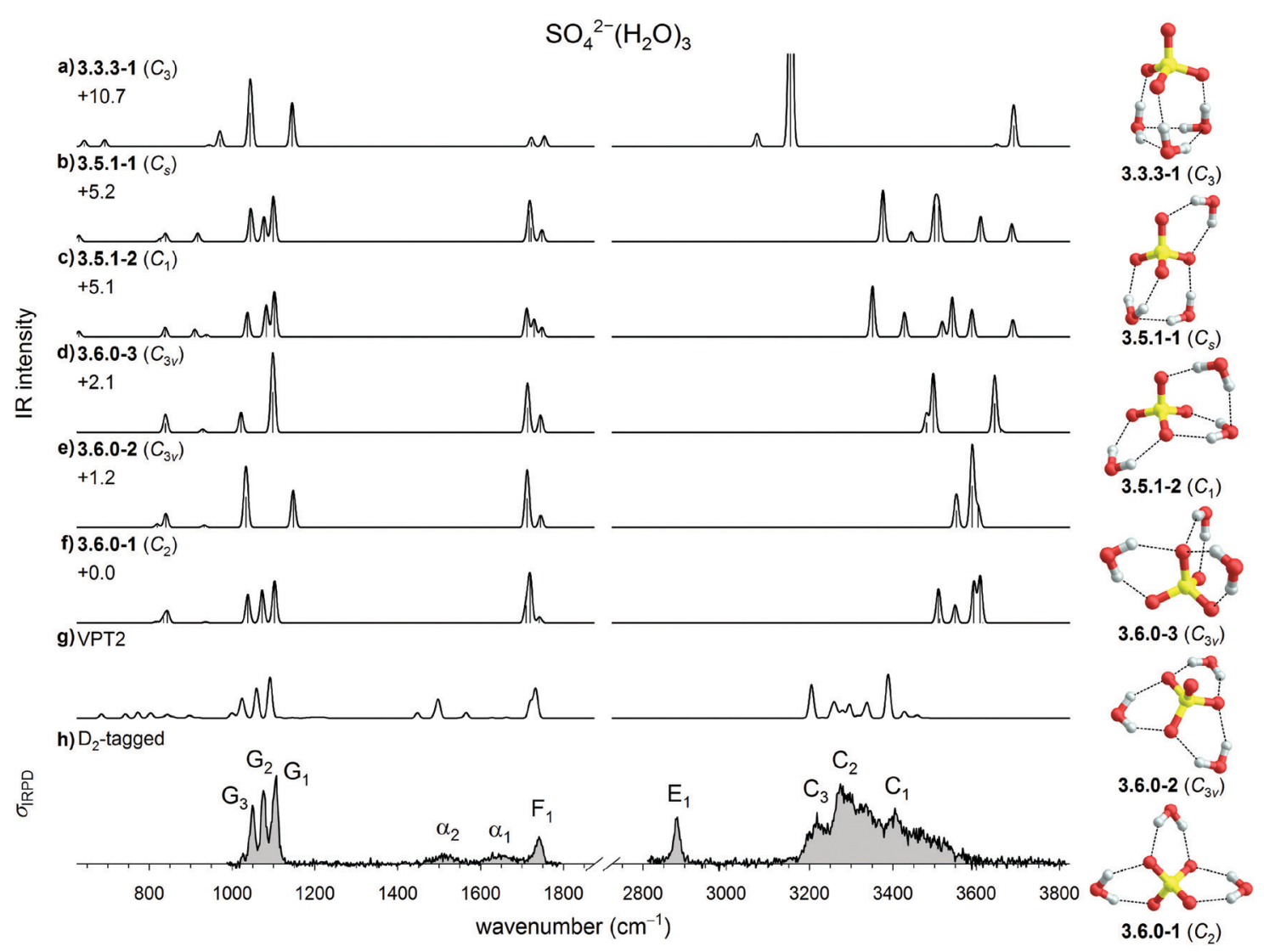

Fig. 4 Comparison of experimental and computed vibrational spectra of $\mathrm{SO}_{4}{ }^{2-}\left(\mathrm{H}_{2} \mathrm{O}\right)_{3}$ : (a-f) harmonic B3LYP/6-311++G(3df,3pd) IR spectra of six low energy isomers of bare $\mathrm{SO}_{4}{ }^{2-}\left(\mathrm{H}_{2} \mathrm{O}\right)_{3},(\mathrm{~g}) \mathrm{B} 3 \mathrm{LYP} / \mathrm{VPT} 2 \mathrm{IR}$ spectrum of 3.6.0-1 and (h) the IRPD spectrum of $\mathrm{D}_{2}$-tagged $\mathrm{SO}_{4}{ }^{2-}\left(\mathrm{H}_{2} \mathrm{O}\right)_{3}$. Minimum-energy structures, molecular symmetry groups and ZPE-corrected relative $\operatorname{CCSD}(\mathrm{T})$ electronic energies (in $\mathrm{kJ} \mathrm{mol}^{-1}$ ) are also shown. 
structures 3.5.1-2 $\left(+5.1 \mathrm{~kJ} \mathrm{~mol}^{-1}, C_{1}\right)$ and 3.5.1-1 $\left(+5.2 \mathrm{~kJ} \mathrm{~mol}^{-1}, C_{\mathrm{s}}\right)$ and the $\mathrm{W}_{3}$ structure 3.3.3-1 $\left(+5.1 \mathrm{~kJ} \mathrm{~mol}^{-1}, C_{3}\right)$. The barrier between the two lowest energy isomers is $9 \mathrm{~kJ} \mathrm{~mol}^{-1}$.

The IRPD spectrum exhibits an evenly spaced triplet of peaks in the sulfate stretching region, characteristic of a low symmetry structure. This pattern is in agreement with the harmonic spectrum of 3.6.0-1, and disagrees with the spectra of the higher symmetric $3 \mathrm{~W}_{1}$ and $\mathrm{W}_{3}$ isomers 3.6.0-2, 3.6.0-3, and 3.3.3-1. It also agrees less well with the $\mathrm{W}_{2}+\mathrm{W}_{1}$ isomers 3.5.1-2 and 3.5.1-1. The remaining IRPD features in the mid-IR region can be assigned, once static anharmonic effects are considered. The VPT2 IR spectrum of 3.6.0-1 not only reproduces the form and relative intensity of the water bending band at $1741 \mathrm{~cm}^{-1}$, but also identifies bands $\alpha_{1}$ and $\alpha_{2}$ as combination bands and overtones for the three water wagging modes and the minor feature at $1026 \mathrm{~cm}^{-1}$ as a combination of the $\mathrm{SO}_{4}$ bend $\left(\sim 600 \mathrm{~cm}^{-1}\right)$ and water rocking modes $\left(\sim 400 \mathrm{~cm}^{-1}\right)$. Remarkably, this VPT2 spectrum also qualitatively reproduces the position of the broad feature in $\mathrm{OH}$ stretching region $(3170$ to $3600 \mathrm{~cm}^{-1}$ ), suggesting a tentative assignment of features $C_{1}$ $\left(3405 \mathrm{~cm}^{-1}\right)$ to symmetric and $C_{3}\left(3220 \mathrm{~cm}^{-1}\right)$ to antisymmetric $\mathrm{OH}$ stretching modes, while $C_{2}\left(3280 \mathrm{~cm}^{-1}\right)$ is associated with combination bands of the antisymmetric $\mathrm{OH}$ stretching modes with low frequency intermolecular sulfate-water stretches.
Interestingly, also for $n=3$ the all- $\mathrm{W}_{1}$ structure (3.6.0-1) is found to be quite fragile with respect to isomerization in the AIMD simulations; It transforms into the $\mathrm{W}_{3}$ structure 3.3.3-1 at temperatures higher than $20 \mathrm{~K}$ and the corresponding DTCF spectrum is therefore not shown in Fig. 4.

3.2.4. $\mathrm{SO}_{4}{ }^{2-}\left(\mathrm{H}_{2} \mathrm{O}\right)_{5}$. The five lowest energy $n=5$ structures and their relative energies are shown in Fig. 5. A large variety of qualitatively different structural isomers is observed. Isomers exhibiting the three different motifs $\mathrm{W}_{3}+2 \mathrm{~W}_{1}$ (5.7.3-1), $\mathrm{W}_{2}+3 \mathrm{~W}_{1}(\mathbf{5 . 9 . 1 - 1})$ and $5 \mathrm{~W}_{1}(\mathbf{5 . 1 0 . 0}-1)$ are predicted within less than $1 \mathrm{~kJ} \mathrm{~mol}^{-1}$ of each other. Moreover, $2 \mathrm{~W}_{2}+\mathrm{W}_{1}(\mathbf{5 . 7 . 3 - 2})$ and $\mathrm{W}_{3}+\mathrm{W}_{2}$ (5.6.4-5) structures are calculated within $7 \mathrm{~kJ} \mathrm{~mol}^{-1}$. Structure 5.7.3-1 $\left(C_{1}\right)$ represents the global ground state and lies $0.8 \mathrm{~kJ} \mathrm{~mol}^{-1}$ below 5.9.1-1 $\left(C_{\mathrm{s}}\right)$.

The harmonic IR spectra of the five lowest energy $n=5$ structures are compared to the IRPD spectrum of $\mathrm{D}_{2}$-tagged $\mathrm{SO}_{4}{ }^{2-}\left(\mathrm{H}_{2} \mathrm{O}\right)_{5}$ in Fig. 5. Due to the overall low symmetry of the $n=5$ isomers the assignment is not as straight forward as for the other $n \leq 6$ systems. Inspection of the sulfate antisymmetric stretch triplet suggests an assignment to either the 5.7.3-1 (Fig. 5e) or 5.10.0-1 isomer (Fig. 5c), which both reproduce the relative peak spacings and intensities satisfactorily. Both of these harmonic spectra also recover the width of the water bend band $F_{1}$, whereas the relative intensity (with respect to bands $G_{1-3}$ ) is

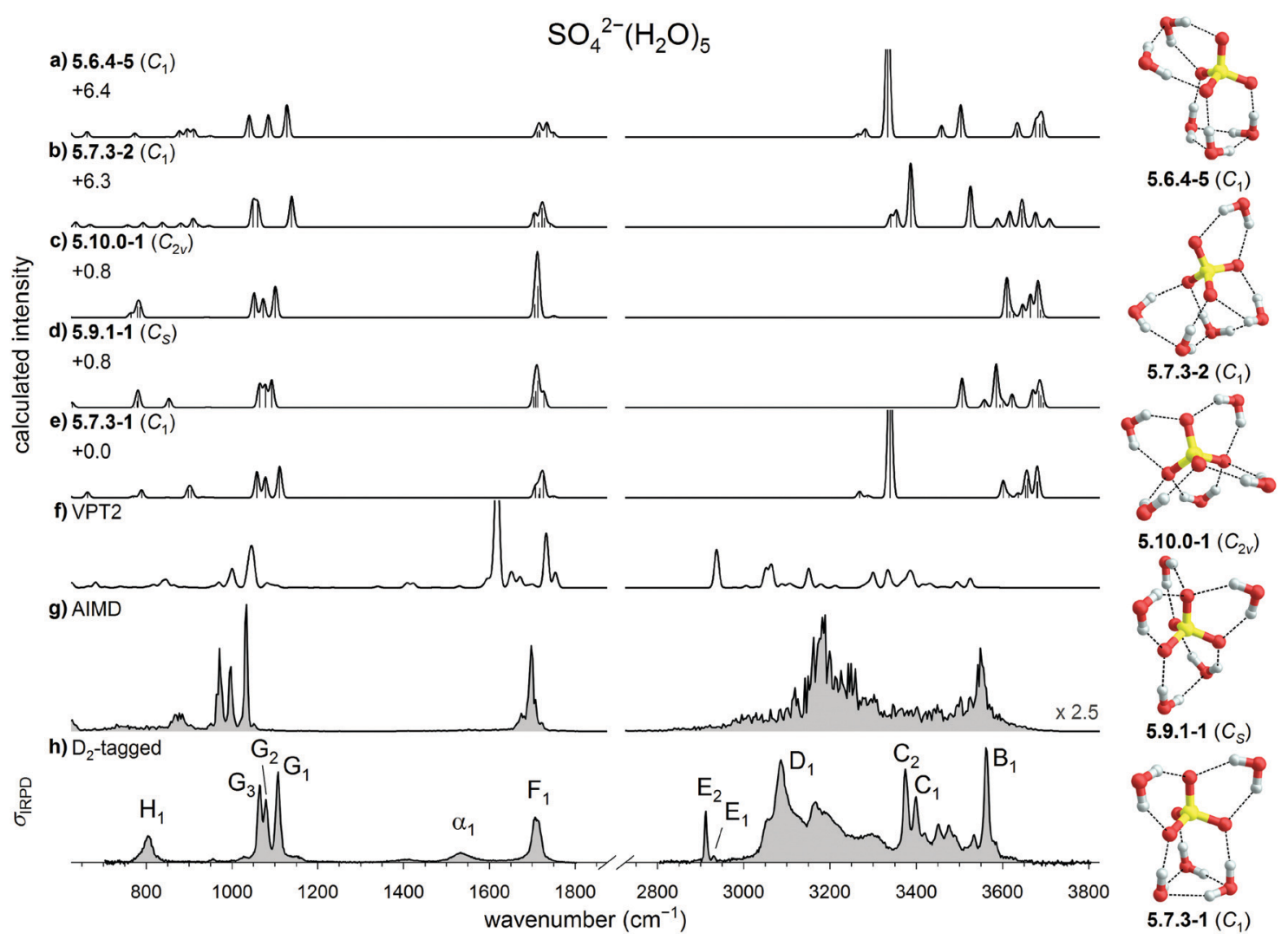

Fig. 5 Comparison of experimental and computed vibrational spectra of $\mathrm{SO}_{4}{ }^{2-}\left(\mathrm{H}_{2} \mathrm{O}\right)_{5}$ : (a-e) harmonic B3LYP/6-311++G(3df,3pd) IR spectra of five low energy isomers of bare $\mathrm{SO}_{4}{ }^{2-}\left(\mathrm{H}_{2} \mathrm{O}\right)_{5}$, (f) B3LYP/VPT2 IR spectrum of 5.7.3-1, (g) DTCF spectrum of 5.7.3-1 and (h) the IRPD spectrum of $\mathrm{D}_{2}$-tagged $\mathrm{SO}_{4}{ }^{2-}\left(\mathrm{H}_{2} \mathrm{O}\right)_{5}$. Minimum-energy structures, molecular symmetry groups and ZPE-corrected relative CCSD(T) electronic energies (in $\mathrm{kJ}^{\mathrm{mol}}{ }^{-1}$ ) are also shown. 
better reproduced by the 5.7.3-1 spectrum. However, this spectrum predicts two low-intensity wagging bands, one from the $\mathrm{ADD}$-water $\left(\mathrm{W}_{3}\right.$ motif) and the other from the DD-water ( $W_{1}$ motif), at $903 \mathrm{~cm}^{-1}$ and $790 \mathrm{~cm}^{-1}$, respectively. The latter is nearly absent from the present IRPD spectrum. Indeed, the absence of this band in the previously published IRMPD spectrum had resulted in exclusion of this isomer in the previous study. ${ }^{14}$ More recently, however, we showed that dynamic effects, which are present in all of the systems, lead to a substantial broadening of the DD-water wagging bands, while the ADD water wags are less affected and therefore more easily identified. ${ }^{21}$ The number of observed water wagging bands does therefore not allow for a conclusive assignment and additional information is required.

As we noted already in Section 3.1.1, the IRPD spectrum shows a characteristically broad $\mathrm{OH}$ stretch absorption features extending down to $3000 \mathrm{~cm}^{-1}$. This feature cannot be rationalized by an all- $\mathrm{W}_{1}$ motif, like $\mathbf{5 . 1 0 . 0 - 1}$, but rather requires the presence of stronger inter-water HBs, like in 5.7.3-1. To find additional evidence we turn to the anharmonic calculations. The VPT2 results (see Fig. $5 f$ ) are not conclusive. While they do predict broad IR activity in the $\mathrm{OH}$ stretching region, i.e. down to $2900 \mathrm{~cm}^{-1}$, the agreement in the fingerprint region that is present at the harmonic level is surprisingly lost. The results of the AIMD simulations, on the other hand, do lend additional support to the 5.7.3-1 assignment. The corresponding DTCF spectrum indeed qualitatively recovers most of the features of the IRPD spectrum across the complete spectral range. Moreover, it is characterized by a sharp feature at $\sim 3550 \mathrm{~cm}^{-1}$ and strong IR activity around $3200 \mathrm{~cm}^{-1}$ and below. These features are characteristic signatures of the $\mathrm{W}_{3}$ motif and correspond to excitation of equatorial $\left(\mathrm{B}_{1}\right)$ and axial $\left(\mathrm{D}_{1}\right) \mathrm{OH}$-stretches in the IRPD spectrum. Compared to the IR signature of $\mathrm{W}_{3}$ in the $n=6$ spectrum, $D_{1}$ shifts to the red by $\sim 90 \mathrm{~cm}^{-1}$ and is broader, in line with the expectation that the $\mathrm{W}_{3}-\mathrm{SO}_{4}{ }^{2-}$ interaction is stronger in $n=5$ than in $n=6 .{ }^{21}$ More extensive inter-water HB interactions in $n=5$ also lead to the increase in intensity of the water wagging band $(\mathrm{H})$. However, also this spectrum does not show quantitative agreement. For instance, the experimental bands $\mathrm{C}_{1}$ and $\mathrm{C}_{2}$ are not satisfactorily reproduced by this AIMD simulation. That, in particular, these bands show a marked temperature-dependence is known from our previous study $^{21}$ on $n=6$ and confirmed by the temperature-dependent IRMPD spectra of $\mathrm{SO}_{4}{ }^{2-}\left(\mathrm{H}_{2} \mathrm{O}\right)_{5}$ measured from 6 to $150 \mathrm{~K}$ (see Fig. S3, ESI $\dagger$ ). The marked broadening with increasing temperature is attributed to efficient excitation of large amplitude motion of the two $\mathrm{W}_{1}$ motifs. Isomer-selective measurements (Fig. S5, ESI $\dagger$ ), similar to those previously discussed for $n=6,{ }^{21}$ demonstrate that indeed only a single isomer is probed. Note, these double resonance measurements are sensitive to

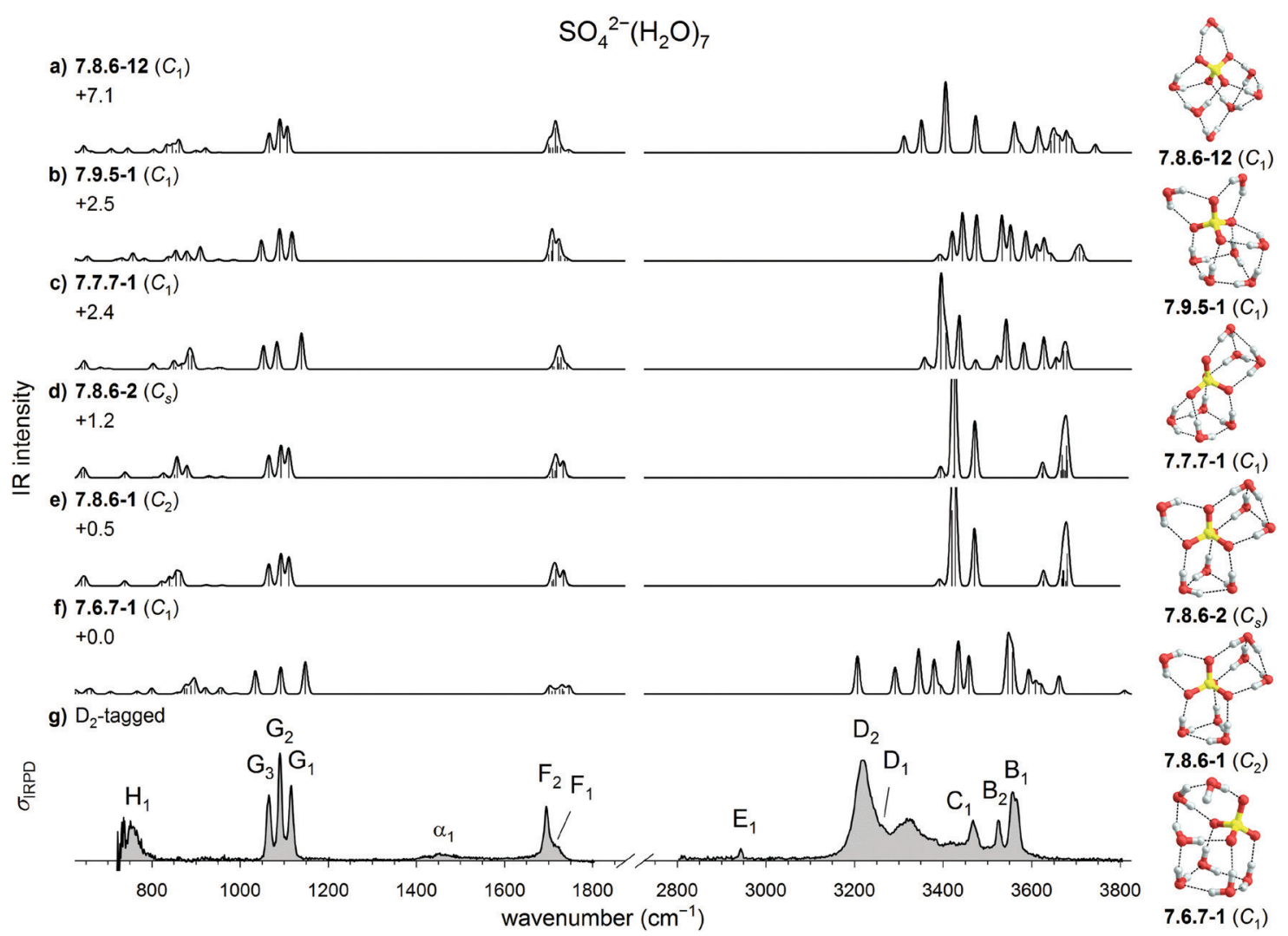

Fig. 6 Comparison of experimental and computed vibrational spectra of $\mathrm{SO}_{4}{ }^{2-}\left(\mathrm{H}_{2} \mathrm{O}\right)_{7}$ : (a-f) harmonic B3LYP/6-311++G(3df,3pd) IR spectra of six low energy isomers of bare $\mathrm{SO}_{4}{ }^{2-}\left(\mathrm{H}_{2} \mathrm{O}\right)_{7}$ and $(\mathrm{g})$ the IRPD spectrum of $\mathrm{D}_{2}$-tagged $\mathrm{SO}_{4}{ }^{2-}\left(\mathrm{H}_{2} \mathrm{O}\right)_{7}$. Minimum-energy structures, molecular symmetry groups and ZPE-corrected relative B3LYP electronic energies (in $\mathrm{kJ} \mathrm{mol}^{-1}$ ) are also shown. 
laser-induced population changes that are maintained longer than the delay between the two IR laser pulses $\left(\sim 10^{-5} \mathrm{~s}\right)$. The IR spectra of more quickly interconverting isomers cannot be isolated using this technique.

3.2.5. SO $_{4}{ }^{2-}\left(\mathbf{H}_{2} \mathbf{O}\right)_{6}$. Results for the $n=6$ complex have been presented and analyzed previously. ${ }^{21}$ The structures of all cluster sizes will be compared later in the paper.

3.2.6. $\mathrm{SO}_{4}{ }^{2-}\left(\mathrm{H}_{2} \mathrm{O}\right)_{7}$. As highly accurate electronic energies are only available up to $n=6,{ }^{31}$ we re-optimized 39 possible isomers of $\mathrm{SO}_{4}{ }^{2-}\left(\mathrm{H}_{2} \mathrm{O}\right)_{7}$ reported in ref. 30 using the B3LYP+GD3BJ/6-311++G(3df,3pd) method. The six lowest energy structures and their relative B3LYP energies are shown in Fig. 6. Comparison of B3LYP energies with the highly accurate theoretical results available for smaller clusters showed deviation of $\pm 3 \mathrm{~kJ} \mathrm{~mol}^{-1}$ in relative energies and we therefore we do not expect these energies to predict the energetic order reliably. The lowest energy isomer predicted is 7.6.7-1, in which all water molecules are part of a single HBed network. Minimally higher in energy are two $2 \mathrm{~W}_{3}+\mathrm{W}_{1}$ and a $\mathrm{W}_{4}+\mathrm{W}_{3}$ isomers.

Fig. 6 compares the experimental IRPD spectra for $n=7$ to the harmonic IR spectra of these energetically low-lying isomers. Inspection of the sulfate stretch region allows to eliminate $7.6 .7-1$ and $7.7 .7-1$ from the list of possible candidates. Best agreement is found for 7.8.6-1 and 7.8.6-2. Both have nearly identical IR spectra and only differ in the orientation of the two $\mathrm{W}_{3}$ motifs relative to each other. The higher energy isomer 7.8.6-12, which shows comparably good agreement in the sulfate stretch region, does not contain an undistorted $\mathrm{W}_{3}$ motif, but a quasi-free $\mathrm{OH}$ moiety, for which no evidence is found in the experimental spectrum. Such a quasifree $\mathrm{OH}$ oscillator was observed for $n=8$ and is discussed in the following section. The presence of feature $\mathrm{D}$ in the $\mathrm{OH}$ stretching region, just like for the IRPD spectra of $n=5$ and $n=6$, lends further support for the presence of $\mathrm{W}_{3}$ motifs and thus an assignment to either 7.8.6-1 or 7.8.6-2. Compared to the IRPD spectrum of $n=6$, peak B is shifted to the red by only $3 \mathrm{~cm}^{-1}$, indicating that the equatorial and inter-water $\mathrm{HBs}$ in $\mathrm{W}_{3}$ remain about the same. Peak D, on the other hand is shifted to the blue by $47 \mathrm{~cm}^{-1}$, indicating further weakening of the axial $\mathrm{HB}$ solvating $\mathrm{SO}_{4}{ }^{2-}$. Unlike the spectrum for $n=5$, there is no strong peak around $3400 \mathrm{~cm}^{-1}$, and probably no contribution from $\mathrm{W}_{2}$. Peaks $\mathrm{C}_{1}$ and $\mathrm{C}_{2}$ are likely due to the $\mathrm{W}_{1}$-motif.

3.2.7. $\mathrm{SO}_{4}{ }^{2-}\left(\mathrm{H}_{2} \mathrm{O}\right)_{8}$. Since there is no pool of potential structures available for $\mathrm{SO}_{4}{ }^{2-}\left(\mathrm{H}_{2} \mathrm{O}\right)_{8}$, we performed $\mathrm{MD}$ simulations to

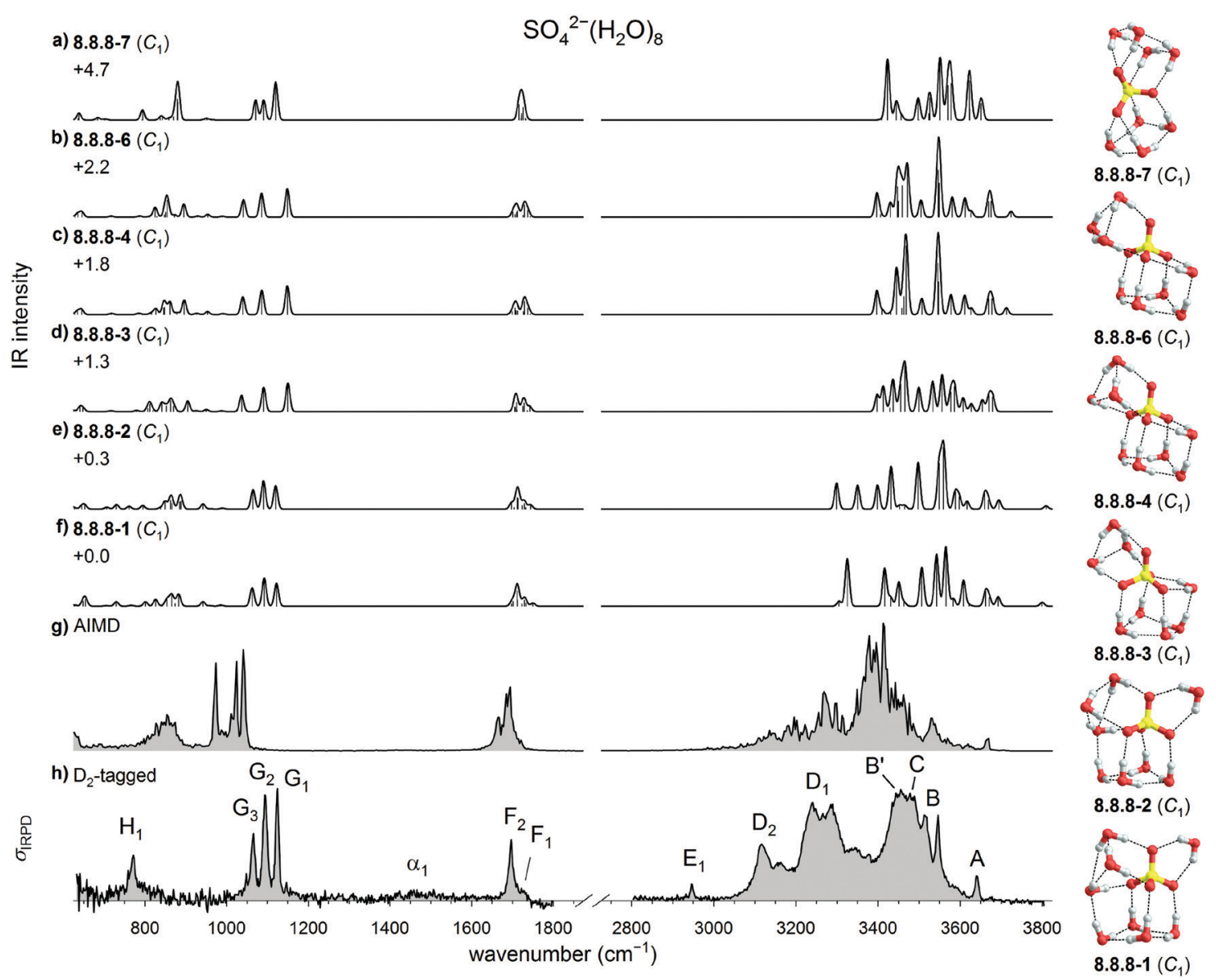

Fig. 7 Comparison of experimental and computed vibrational spectra of $\mathrm{SO}_{4}{ }^{2-}\left(\mathrm{H}_{2} \mathrm{O}\right)_{8}$ : (a-f) harmonic B3LYP/6-311++G(3df,3pd) IR spectra of six low energy isomers of bare $\mathrm{SO}_{4}{ }^{2-}\left(\mathrm{H}_{2} \mathrm{O}\right)_{8}$ (g) DTCF spectrum of 8.8.8-1 and (h) the IRPD spectrum of $\mathrm{D}_{2}$-tagged $\mathrm{SO}_{4}{ }^{2-}\left(\mathrm{H}_{2} \mathrm{O}\right)_{8}$. Minimum-energy structures, molecular symmetry groups and ZPE-corrected relative B3LYP electronic energies (in $\mathrm{kJ} \mathrm{mol}^{-1}$ ) are also shown. The labels in the $\mathrm{OH}$ stretch region are based on the trends shown in Fig. 1. 
generate structural candidates, of which 24 structures were then calculated more precisely. The six lowest energy isomers are shown in Fig. 7, the five lowest of them lie within $3 \mathrm{~kJ} \mathrm{~mol}^{-1}$. All of these structures contain eight inter-water HBs. 8.9.7- $x$ and 8.7.9- $x$ structures are more than $5.0 \mathrm{~kJ} \mathrm{~mol}^{-1}$ higher in energy compared to the lowest energy isomer. The two lowest energy isomers share a common motif, not observed for the structures assigned to the spectra of all smaller $(n<8)$ systems. The motif consists of a quasi-planar $\mathrm{W}_{4}$ ring as part of cube spawned by eight $\mathrm{O}$-atoms, three from the sulfate dianion and the rest from five water molecules. The individual structures differ in the arrangement of the remaining water molecules, which can assemble in the form of additional $\mathrm{W}_{1}, \mathrm{~W}_{3}$, and $\mathrm{W}_{4}$ units.

Inspection of the sulfate stretching region for $n=8$ (see Fig. 7) reveals that the IR spectra of the two lowest energy structures 8.8.8-1 and 8.8.8-2 yield much better agreement with the experimental IRPD spectrum than the those of the next three isomers (see Table S7, ESI $\dagger$ ). As already noted in Section 3.1.1, the monotonic blue-shift of band $\mathrm{D}$ in the $n=5$ to $n=7$ spectra does not continue for $n=8$. This features actually splits into two components, $\mathrm{D}_{1}$ and $\mathrm{D}_{2}$, of which the first falls in line with the previously described blue-shift and the other appears at the same position as for $n=5$. This must be due to the $\mathrm{W}_{4}$ motif of the 8.8.8 isomers. Note, there is now one water molecule that is not directly $\mathrm{HBed}$ to $\mathrm{SO}_{4}{ }^{2-}$. In this sense, $n=8$ represents the onset for the formation of the second solvation shell, with some HBs strengthened, as indicated by the blue-shift of band $D_{2}$. Other HBs are weakened, as indicated by the first appearance of a band as high as $3640 \mathrm{~cm}^{-1}\left(\mathrm{~A}_{1}\right)$ and attributed to excitation of a quasi-free $\mathrm{OH}$ stretch oscillator involved in an unusually long $(2.5 \AA)$ equatorial $\mathrm{W}_{3}$-HB. Bands $\mathrm{B}_{1}\left(3546 \mathrm{~cm}^{-1}\right)$ and $\mathrm{D}_{1}\left(3240 \mathrm{~cm}^{-1}\right)$ are also attributed to this $\mathrm{W}_{3}$ motif.

Further support for this assignment comes from the AIMD simulation involving the 8.8.8-1. The corresponding DTCF spectrum is shown in Fig. 7 and nicely reproduces the above mentioned five features in the $\mathrm{OH}$-stretch region. Moreover, these simulations show that this structure is stable up to $200 \mathrm{~K}$, after which the $\mathrm{W}_{1}$ moiety forms a new $\mathrm{HB}$ to another water molecule, while the other motifs remain stable.

\subsection{Microhydration trends}

The present results show that caution is required in using individual harmonic IR spectra in the $\mathrm{OH}$ stretching region for a structure assignment. However, they remain helpful in identifying qualitative trends when they are viewed as part of a series of spectra, as shown in Fig. 8. The spectral evolution with cluster size of band $\mathrm{D}$, which is associated with the $\mathrm{W}_{3}$ motif, is highlighted by the gray-shaded bar. The observed experimental pattern is indeed consistent with the trend predicted in the harmonic spectra, i.e. the evolution of $\mathrm{W}_{1}$-only structures $(n=3,4)$ over isolated $\mathrm{W}_{3}$-structures $(n=5-7)$ to structures with more extended hydrogen-bonded networks $(n \geq 8)$ :

$$
\begin{gathered}
3 \mathrm{~W}_{1} \stackrel{+\mathrm{W}}{\longrightarrow} 4 \mathrm{~W}_{1} \stackrel{+\mathrm{W}}{\longrightarrow} \mathrm{W}_{3}+2 \mathrm{~W}_{1} \stackrel{+\mathrm{W}}{\longrightarrow} \mathrm{W}_{3}+3 \mathrm{~W}_{1} \\
\stackrel{+\mathrm{W}}{\longrightarrow} 2 \mathrm{~W}_{3}+\mathrm{W}_{1} \stackrel{+\mathrm{W}}{\longrightarrow}\left(\mathrm{W}_{4} / \mathrm{W}_{3}\right)+\mathrm{W}_{1} .
\end{gathered}
$$

The $\mathrm{W}_{3}$ motif appears first for $n=5$. Additional water molecules weaken the interaction with the three-membered water ring and therefore strengthen the $\mathrm{OH}$ bonds oriented towards the sulfate dianion and hence the corresponding vibrational frequencies are
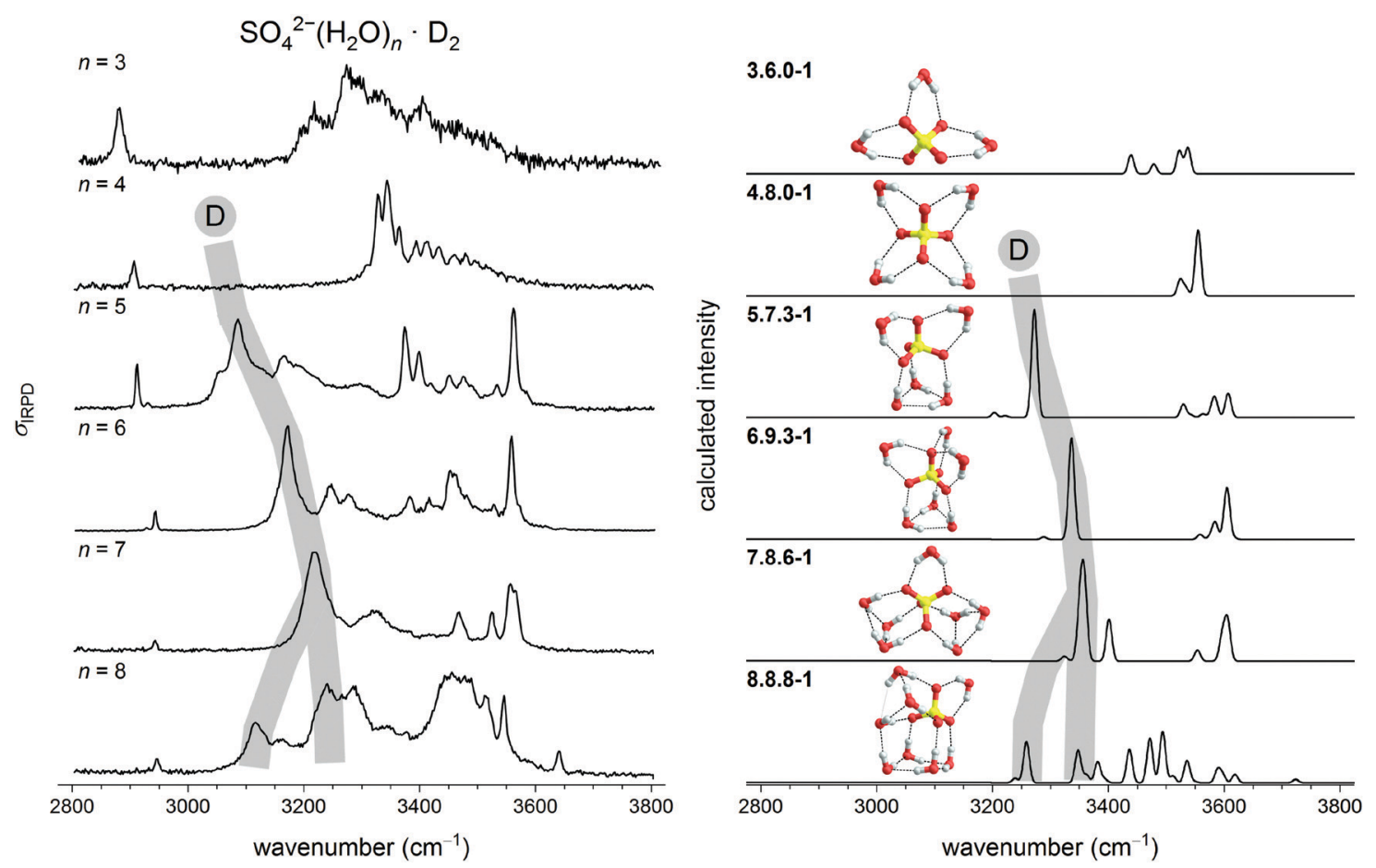

Fig. 8 Comparison of the IRPD spectra (left) to the corresponding harmonic B3LYP IR spectra (right) of the assigned structures for $\mathrm{SO}_{4}{ }^{2-}\left(\mathrm{H}_{2} \mathrm{O}\right)_{n}$ $(n=3-8)$ in the $\mathrm{OH}$ stretching region. The gray-shaded areas highlight IR-active bands associated with the $\mathrm{W}_{3}$ motif. 
shifted systematically to higher wavenumbers. This trend is stopped at $n=8$ with the first appearance of a $\mathrm{W}_{4}$ motif, which perturbs and weakens the interaction between sulfate and the $\mathrm{W}_{3}$-ring.

Overall, the present IRPD spectra are qualitatively different from those of comparable systems, like microhydrated halide ${ }^{63}$ or perchlorate anions. ${ }^{64}$ In particular, the present spectra are characterized by broader and more red-shifted $\mathrm{OH}$ stretching bands. This is a direct result of the stronger ion-water interactions in microhydrated sulfate dianions, which leads to marked coupling of the $\mathrm{OH}$ oscillators with low frequency modes, in particular, of isolated DD- $\mathrm{H}_{2} \mathrm{O}$ molecules, ${ }^{65,66}$ but also of water molecules that are part of larger HBed networks. ${ }^{67,68}$ Moreover, the water bending features are found at higher frequencies compared to the corresponding bands in the spectra of hydrated perchlorate anions (1650 to $\left.1680 \mathrm{~cm}^{-1}\right) .{ }^{64}$

It is also interesting to compare the evolution of the antisymmetric stretch frequencies $\nu_{\mathrm{AS}}$ of the tetrahedral core with the degree of microhydration. In microhydrated sulfate dianions the observed splitting of the $\nu_{\text {AS }}$ peaks is significantly smaller than in the perchlorate monoanion, ${ }^{64}$ directly reflecting the tendency of water molecules to distribute around a sulfate dianion, while they aggregate on one side of the perchlorate anion. The more symmetric microhydration represents another manifestation of the stronger solute-solvent interactions in the microhydrated sulfate dianions. However, the present results also highlight that the most stable structures are not obtained by exclusively maximizing the number of dianion-water HBs, but the formation of stable three- and four-membered water rings containing strong water-water interactions also needs to be considered. ${ }^{16,18}$

\section{Conclusions}

$\mathrm{D}_{2}$-tagging microhydrated sulfate dianions introduces a new level of spectral quality in the IRPD spectra of $\mathrm{SO}_{4}{ }^{2-}\left(\mathrm{H}_{2} \mathrm{O}\right)_{3-8}$ compared to previous IRMPD measurements, which enables a more reliable determination of band positions and improved structural assignments. The structures identified here by CIVS confirm most of the original assignments made by Wang et al. for $n=4$ to 7 based on photoelectron spectra of cold anions, except that for $n=5 .{ }^{15}$ Our assignments also differ from those of Lambrecht et al. for $n=4$ and $n=5$. $^{30}$

The basic building blocks found in sulfate microhydration up to $n=8$ are the four motifs $\mathrm{W}_{1-4}$. Their stability results from a competition between the formation slightly stronger sulfatewater HBs with cooperativity-driven formation of water-water HBs. The presence of water rings leads to a characteristic but complex IR fingerprint in the spectral region below $3300 \mathrm{~cm}^{-1}$ due to $\mathrm{OH}$ oscillators of $\mathrm{ADD}-\mathrm{H}_{2} \mathrm{Os}$ HBed to the dianion core. $\mathrm{OH}$ oscillators involved in water-water HBs are found above $3450 \mathrm{~cm}^{-1}$. A quasi-free $\mathrm{OH}$ oscillator is observed for $n=8$, i.e., at smaller sizes than previously predicted. ${ }^{27} \mathrm{SO}_{4}{ }^{2-}\left(\mathrm{H}_{2} \mathrm{O}\right)_{8}$ also represents the smallest cluster containing a water molecule not directly bound to the sulfate dianion core and therefore the onset for the formation of a second hydration shell (before the first one is completed). This observation is in agreement with the notion that charge transfer from the dianion core to the water network is complete at $n=7 .^{28}$

We emphasize that the comparison of harmonic spectra to experimental IR spectra for individual cluster sizes typically does not lead to a conclusive structure assignment, but that series of predicted harmonic spectra remain helpful in identifying trends. Static anharmonic calculations can be helpful in assigning IR bands, in particular in the fingerprint region, but molecular dynamics simulations are required to attempt to disentangle the wealth of information contained in the $\mathrm{OH}$ stretching region.

\section{Conflicts of interest}

There are no conflicts to declare.

\section{Acknowledgements}

This work has been supported by the German Research Foundation (DFG) as part of the individual research Grant No. AS133/3-1 "Spectroscopic Characterization of Salt Dissolution in Microhydrated Cluster Ions and at the Water/Vapor Interface." ZFL thanks the support from the National Natural Science Foundation of China (Grant No. 21473151) and from CUHK through a Direct Grant (3132676). J. W. is grateful for a Freigeist Fellowship of the Volkswagen Foundation. The authors are thankful to Alexandra Giermann (Universität Leipzig) for her assistance in preparing and handling sulfuric acid solutions. K. R. A. acknowledges instrumental support from the Fritz-Haber-Institute of the Max-Planck Society.

\section{References}

1 V. Ramanathan, P. J. Crutzen, J. T. Kiehl and D. Rosenfeld, Science, 2001, 294(5549), 2119.

2 A. Lee, P. A. Dawson and D. Markovich, Int. J. Biochem. Cell Biol., 2005, 37(7), 1350.

3 S. W. Squyres, J. P. Grotzinger, R. E. Arvidson, J. F. Bell, W. Calvin, P. R. Christensen, B. C. Clark, J. A. Crisp, W. H. Farrand, K. E. Herkenhoff, J. R. Johnson, G. Klingelhöfer, A. H. Knoll, S. M. McLennan, H. Y. McSween, R. V. Morris, J. W. Rice, R. Rieder and L. A. Soderblom, Science, 2004, 306(5702), 1709.

4 Y. Zhang and P. S. Cremer, Curr. Opin. Chem. Biol., 2006, 10(6), 658.

5 A. T. Blades and P. Kebarle, J. Am. Chem. Soc., 1994, 116(23), 10761.

6 W. R. Cannon, B. M. Pettitt and J. A. McCammon, J. Phys. Chem., 1994, 98(24), 6225.

7 X.-B. Wang, X. Yang and L.-S. Wang, Int. Rev. Phys. Chem., 2002, 21(3), 473.

8 K. R. Asmis and D. M. Neumark, Acc. Chem. Res., 2012, 45(1), 43. 
9 M. J. DiTucci, C. N. Stachl and E. R. Williams, Chem. Sci., 2018, 9(16), 3970.

10 X.-B. Wang, J. B. Nicholas and L.-S. Wang, J. Chem. Phys., 2000, 113(24), 10837.

11 X. B. Wang, X. Yang, J. B. Nicholas and L. S. Wang, Science, 2001, 294(5545), 1322.

12 X. Yang, X.-B. Wang and L.-S. Wang, J. Phys. Chem. A, 2002, 106(33), 7607.

13 R. L. Wong and E. R. Williams, J. Phys. Chem. A, 2003, 107(50), 10976.

14 J. Zhou, G. Santambrogio, M. Brümmer, D. T. Moore, L. Wöste, G. Meijer, D. M. Neumark and K. R. Asmis, J. Chem. Phys., 2006, 125(11), 111102.

15 X.-B. Wang, A. P. Sergeeva, J. Yang, X.-P. Xing, A. I. Boldyrev and L.-S. Wang, J. Phys. Chem. A, 2009, 113(19), 5567.

16 M. F. Bush, R. J. Saykally and E. R. Williams, J. Am. Chem. Soc., 2007, 129(8), 2220.

17 J. T. O'Brien, J. S. Prell, M. F. Bush and E. R. Williams, J. Am. Chem. Soc., 2010, 132(24), 8248.

18 F. Thaunay, A. A. Hassan, R. J. Cooper, E. R. Williams, C. Clavaguéra and G. Ohanessian, Int. J. Mass Spectrom., 2017, 418, 15.

19 B. Gao and Z.-F. Liu, J. Chem. Phys., 2005, 123(22), 224302.

20 Y. Miller, G. M. Chaban, J. Zhou, K. R. Asmis, D. M. Neumark and R. B. Gerber, J. Chem. Phys., 2007, $127(9), 94305$.

21 H. Knorke, H. Li, Z.-F. Liu and K. R. Asmis, Phys. Chem. Chem. Phys., 2019, 21(22), 11651.

22 C.-G. Zhan, F. Zheng and D. A. Dixon, J. Chem. Phys., 2003, 119(2), 781.

23 C. C. Pye and W. W. Rudolph, J. Phys. Chem. A, 2001, 105(5), 905.

24 B. Gao and Z.-F. Liu, J. Chem. Phys., 2004, 121(17), 8299.

25 P. Jungwirth, J. E. Curtis and D. J. Tobias, Chem. Phys. Lett., 2003, 367(5-6), 704.

26 F. Thaunay, C. Clavaguéra and G. Ohanessian, Phys. Chem. Chem. Phys., 2015, 17(39), 25935.

27 L. C. Smeeton, J. D. Farrell, M. T. Oakley, D. J. Wales and R. L. Johnston, J. Chem. Theory Comput., 2015, 11(5), 2377.

28 M. Kulichenko, N. Fedik, K. V. Bozhenko and A. I. Boldyrev, J. Phys. Chem. B, 2019, 123(18), 4065.

29 N. Mardirossian, D. S. Lambrecht, L. McCaslin, S. S. Xantheas and M. Head-Gordon, J. Chem. Theory Comput., 2013, 9(3), 1368.

30 D. S. Lambrecht, G. N. I. Clark, T. Head-Gordon and M. Head-Gordon, J. Phys. Chem. A, 2011, 115(41), 11438.

31 D. S. Lambrecht, L. McCaslin, S. S. Xantheas, E. Epifanovsky and M. Head-Gordon, Mol. Phys., 2012, 110(19-20), 2513.

32 N. Heine and K. R. Asmis, Int. Rev. Phys. Chem., 2015, 34(1), 1.

33 N. Heine and K. R. Asmis, Int. Rev. Phys. Chem., 2016, 35(3), 507.

34 T. K. Esser, H. Knorke, F. Siro-Brigiano, D. R. Galimberti, K. R. Asmis, M.-P. Gaigeot and J. M. Lisy, Phys. Chem. Chem. Phys., 2018, 20(45), 28476.

35 M. Brümmer, C. Kaposta, G. Santambrogio and K. R. Asmis, J. Chem. Phys., 2003, 119(24), 12700.
36 D. J. Goebbert, T. Wende, R. Bergmann, G. Meijer and K. R. Asmis, J. Phys. Chem. A, 2009, 113(20), 5874.

37 W. R. Bosenberg and D. R. Guyer, J. Opt. Soc. Am. B, 1993, 10(9), 1716.

38 M. J. Frisch, G. W. Trucks, H. B. Schlegel, G. E. Scuseria, M. A. Robb, J. R. Cheeseman, G. Scalmani, V. Barone, G. A. Petersson and H. Nakatsuji, Gaussian Inc., Wallingford, CT, 2016.

39 A. D. Becke, J. Chem. Phys., 1993, 98(7), 5648.

40 R. Krishnan, J. S. Binkley, R. Seeger and J. A. Pople, J. Chem. Phys., 1980, 72(1), 650.

41 M. J. Frisch, J. A. Pople and J. S. Binkley, J. Chem. Phys., 1984, 80(7), 3265.

42 J. Bloino and V. Barone, J. Chem. Phys., 2012, 136(12), 124108.

43 S. Grimme, S. Ehrlich and L. Goerigk, J. Comput. Chem., 2011, 32(7), 1456.

44 J. VandeVondele, M. Krack, F. Mohamed, M. Parrinello, T. Chassaing and J. Hutter, Comput. Phys. Commun., 2005, 167(2), 103.

45 G. Lippert, J. Hutter and M. Parrinello, Theor. Chem. Acc., 1999, 103(2), 124.

46 S. Goedecker, M. Teter and J. Hutter, Phys. Rev. B: Condens. Matter Mater. Phys., 1996, 54(3), 1703.

47 C. Hartwigsen, S. Goedecker and J. Hutter, Phys. Rev. B: Condens. Matter Mater. Phys., 1998, 58(7), 3641.

48 M. Krack, Theor. Chem. Acc., 2005, 114(1), 145.

49 A. D. Becke, Phys. Rev. A: At., Mol., Opt. Phys., 1988, 38(6), 3098.

50 C. Lee, Q. Yang and R. G. Parr, Phys. Rev. B: Condens. Matter Mater. Phys., 1988, 37(2), 785.

51 G. J. Martyna and M. E. Tuckerman, J. Chem. Phys., 1999, $110(6), 2810$.

52 S. Nosé, J. Chem. Phys., 1984, 81(1), 511.

53 D. A. McQuarrie, Statistical Mechanics, Harper and Row, New York, 1976, ch. 21.

54 J.-C. Jiang, Y.-S. Wang, H.-C. Chang, S. H. Lin, Y. T. Lee, G. Niedner-Schatteburg and H.-C. Chang, J. Am. Chem. Soc., 2000, 122(7), 1398.

55 H. Li, X. Kong, L. Jiang and Z.-F. Liu, Phys. Chem. Chem. Phys., 2018, 20(42), 26918.

56 P. J. Brannon, C. H. Church and C. W. Peters, J. Mol. Spectrosc., 1968, 27(1-4), 44.

57 T. Shimanouchi, Tables of molecular vibrational frequencies, National Bureau of Standards, Washington, DC, 1980.

58 M. Heyden, J. Sun, S. Funkner, G. Mathias, H. Forbert, M. Havenith and D. Marx, Proc. Natl. Acad. Sci. U. S. A., 2010, 107(27), 12068.

59 M. Heyden, J. Sun, H. Forbert, G. Mathias, M. Havenith and D. Marx, J. Phys. Chem. Lett., 2012, 3(16), 2135.

60 M. Śmiechowski, J. Sun, H. Forbert and D. Marx, Phys. Chem. Chem. Phys., 2015, 17(13), 8323.

61 E. Garand, T. Wende, D. J. Goebbert, R. Bergmann, G. Meijer, D. M. Neumark and K. R. Asmis, J. Am. Chem. Soc., 2010, $132(2), 849$.

62 M. R. Fagiani, H. Knorke, T. K. Esser, N. Heine, C. T. Wolke, S. Gewinner, W. Schöllkopf, M.-P. Gaigeot, R. Spezia, 
M. A. Johnson and K. R. Asmis, Phys. Chem. Chem. Phys., 2016, 18(38), 26743.

63 W. H. Robertson and M. A. Johnson, Annu. Rev. Phys. Chem., 2003, 54, 173.

64 J. T. Kelly, M. Mayer, A. C. Kennedy, C. Schemel and K. R. Asmis, J. Chem. Phys., 2018, 148(22), 222840.

65 E. M. Myshakin, K. D. Jordan, E. L. Sibert and M. A. Johnson, J. Chem. Phys., 2003, 119(19), 10138.
66 N. Heine, E. G. Kratz, R. Bergmann, D. P. Schofield, K. R. Asmis, K. D. Jordan and A. B. McCoy, J. Phys. Chem. A, 2014, 118(37), 8188.

67 M. A. Boyer, O. Marsalek, J. P. Heindel, T. E. Markland, A. B. McCoy and S. S. Xantheas, J. Phys. Chem. Lett., 2019, 10(5), 918.

68 N. Yang, C. H. Duong, P. J. Kelleher, A. B. McCoy and M. A. Johnson, Science, 2019, 364(6437), 275. 